\title{
First Report of Trypanosoma sp. in Spectacled Caiman (Caiman crocodilus): Morphological and Phylogenetic Relationships
}

\author{
Arlei Marcili, Andrea P. da Costa, Herbert S. Soares, Igor C. L. Acosta, Julia T. R. de Lima, \\ Antonio H. H. Minervino, and Solange M. Gennari
}

Faculdade de Medicina Veterinária e Zootecnia, Universidade de São Paulo, Avenida Prof. Orlando Marques de Paiva 87, Cidade Universitária, 05508-270 São Paulo, SP, Brazil

Correspondence should be addressed to Arlei Marcili; amarcili@usp.br

Received 5 June 2013; Accepted 17 July 2013

Academic Editors: D. Cone, A. Jabbar, G. Mkoji, and P. Somboon

Copyright (C) 2013 Arlei Marcili et al. This is an open access article distributed under the Creative Commons Attribution License, which permits unrestricted use, distribution, and reproduction in any medium, provided the original work is properly cited.

In Crocodylidae family three trypanosomes species were described, T. grayi in African crocodilian and T. cecili and Trypanosoma sp. in Caimans species from Brazil. T. grayi was transmitted by tsetse flies and the vector of Brazilian caimans trypanosomes is unknown. We characterized first Brazilian trypanosome isolated in spectacled caiman (Caiman crocodilus) from Mato Grosso State in Brazil. Morphological findings in epimastigotes forms from axenic culture showed high similarity with Trypanosoma sp. described in Caiman yacare from Brazilian Pantanal. Phylogenetic studies performed with SSU rDNA and gGAPDH (glyceraldehydes-3-phosphato dehydrogenase glycosomal) clustering in T. grayi Clade and together to genotype Cay 01 from Trypanosoma unnamed species isolated in C. yacare. This is the first isolate of Trypanosoma sp. from C. crocodilus and the phylogenetic position with isolates in C. yacare from Pantanal region and demonstrates the low host specificity of cayman trypanosomes in Brazil.

\section{Introduction}

The order Crocodylia includes 23 living species and three families are recognized, Crocodylidae, Gavialidae, and Alligatoridae [1]. Most species of families Crocodylidae and Gavialidae occur in Africa and Asia. Only Alligatoridae occurs in South America and is composed of six species, Paleosuchus palpebrosus, P. trigonatus, Melanosuchus niger, Caiman yacare, C. latirostris, and C. crocodilus [2].

The spectacled caiman (Caiman crocodilus) has the widest distribution of the New World crocodilians with geographic range from southern Mexico to Peru and Brazil. This geographic variability enabled a segregation of this species into four subspecies $[3,4]$. A single subspecies occur in North and Central Brazil, Caiman crocodilus crocodilus [5].

The crocodilians are host to a wide variety of parasites, like intestinal parasites (nematodes and trematodes) [6-10] and hemoparasites (haemogegarines and trypanosomes) [1013 .

The species of genus Trypanosoma are parasites of all vertebrate classes (fish, amphibians, reptiles, birds, and mammals) with life cycles alternating between vertebrates and invertebrates hosts. Most species develop in arthropod vectors, which may belong to different orders and families, while fish, amphibian, and reptiles parasites are transmitted by leeches or insects. Other species are only mechanically transmitted. This genus has several stages, present in different combinations, in blood and/or tissues in the vertebrate and invertebrate hosts [14-19].

In reptiles are described about 80 species of Trypanosoma parasites, including 42 in lizards, 14 in turtles, 21 in snakes, and 3 in crocodilians. The species descriptions are based on morphology of blood forms, host, and geographic origin [20]. In Africa, T. grayi has been described in Osteolaemus tetraspis 
and Crocodilus niloticus, both in family Crocodylidae [21]. In Brazil, Trypanosoma unnamed species was described in Caiman yacare [22] and T. cecili in Caiman crocodilus [13].

Phylogenetic studies performed with a large number of isolates from Africa (T. grayi) and Brazil (Trypanosoma sp.) positioned all sequences from whole SSU rDNA and gGAPDH in a unique monophyletic branch named T. grayi Clade $[19,23,24]$. The Brazilian isolates are segregated in two genotypes, named Cay01 and Cay02, and are different from $T$. grayi isolates [19]. The host of Brazilian trypanosomes isolates is Caiman yacare captured in Pantanal region.

In the present study, we described a first record of Trypanosoma sp. in spectacled caiman (Caiman crocodilus) from Mato Grosso State and addressed the phylogenetic relationships with other crocodilian trypanosomes.

\section{Materials and Methods}

2.1. Study Areas and Capture of Spectacled Caiman. The sample was collected from a single animal captured by ethnic Indians Tapirapé within the area of their Indian reserve in Mato Grosso State, county of Confresa $\left(10^{\circ} 38^{\prime} 22^{\prime \prime} \mathrm{S}\right.$, $\left.51^{\circ} 34^{\prime} 08^{\prime \prime} \mathrm{W}\right)$, composed of a mosaic of Amazonian Rain Forest and Cerrado biomes. The animal included in this study was obtained from legal hunting activity, authorized by IBAMA, held by the indigenous population. Three specimens of $C$. crocodilus, after being handed and immobilized, were anaesthetized and the blood samples and tissue samples (spleen, heart, kidney, lung, and liver) were collected.

\subsection{Isolation in Culture of Trypanosoma sp. from Spectacled} Caiman. For Trypanosoma isolation, blood samples from spectacled caiman (Caiman crocodilus) were inoculated in vacutainer tubes with a biphasic medium containing 15\% of sheep red blood cells with $4 \%$ Blood Agar Base and overlaid with liquid LIT medium supplemented with $20 \%$ of FBS as before [19]. The culture was incubated at $28^{\circ} \mathrm{C}$ and expanded in LIT (Liver Infusion Tryptose) medium for DNA preparation. The isolate (CBT 02) was cryopreserved in liquid nitrogen in the Department of Preventive Veterinary Medicine and Animal Health, Faculty of Veterinary Medicine, University of São Paulo. Samples from cultures were smeared on glass slides and fixed with methanol and stained with Giemsa and photographed.

2.3. Molecular Study. DNA sample was extracted from parasite mass of trypanosome culture using the phenolchloroform method and primary samples were purified using the Wizard DNA Clean-Up System (Promega, Fitchburg, Wisconsin). Extracted DNA samples were subjected to conventional polymerase chain reaction (PCR) targeting a fragment of approximately 900 base pairs (bp) of the V7V8 SSU rDNA [18, 19] and approximately $800 \mathrm{bp}$ of the gGAPDH (glyceraldehydes-3-phosphate dehydrogenase glycosomal) as previously described [23]. PCR products of the expected sizes were purified and sequenced in an automatic sequencer (Applied Biosystems/PerkinElmer, model ABI Prism 310 Genetic, Foster City, CA) according to the manufacturer's recommendations. The nucleotide sequences generated were deposited in GenBank under the accession numbers JQ768791 and JQ768792, respectively, for V7V8 SSU rDNA and gGAPDH genes. These sequences were concatenated and aligned using ClustalX [25] and adjusted manually using GeneDoc software [26] with sequences previously determined from other trypanosomatids species available in Genbank (Table 1). The V7V8 region of SSU rDNA of crocodilian isolates was used to construct a dendogram for intraspecific analysis. The phylogenetic tree was inferred by the maximum parsimony (MP) method using PAUP version $4.0 \mathrm{~b} 10$ [27] with 500 replicates of random addition taxa and TBR branch swapping. Bayesian analysis (B) was performed by Mrs. Bayes v3.1.2 [28] and 1.000.000 generations were employed as using GTR substitution model and four categories range proportion of invariant sites. Posteriori probabilities were used to support branches.

\section{Results}

The positive hemoculture obtained from a single spectacled caiman captured generated one isolate maintained in culture (33\%). Cultures were maintained in axenic medium LIT and used for morphological analysis. Unfortunately, no smears were obtained from the blood of the spectacled caiman. All tissues, including the positive animal, were negative to trypanosome DNA barcoding.

The morphology consisted of epimastigotes with a large kinetoplast positioned near the nucleus and small and narrow undulating membrane (Figure 1) similar to the morphotype 1 in C. yacare trypanosomes previously described [19].

We determined sequences from gGAPDH and SSU rDNA (V7-V8 region) and these sequences were aligned with sequences from different trypanosomatids species retrieved from GenBank (Table 1).

Phylogenetic relationships based on gGAPDH and SSU rDNA sequences inferred by parsimony and Bayesian clustered this new isolate together to the major branch, which corresponds to crocodilian trypanosomes isolates (T. grayi Clade) (Figures 2(a) and 2(b)). The T. grayi Clade included both African crocodilians trypanosomes and American caymans trypanosomes. The isolates from Brazilian caimans were segregated into genotypes assigned Cay01 and Cay02 previously described [19].

Despite distinct host and different geographic origins, the isolate from $C$. crocodilus and Cay01 genotype from C. yacare shared high similarity $(\sim 0.1 \%$ for $\mathrm{gGAPDH}$ and identical SSU rDNA V7-V8 region). Phylogenetic analysis using the concatenated data set of gGAPDH and SSU rDNA genes generated very similar phylogenetic topologies (data not show).

\section{Discussion}

In Brazil only two trypanosomes have been reported in Caiman species based on morphological analysis of blood trypomastigote: unnamed species in C. yacare from Pantanal [22] and Trypanosoma cecili in C. crocodilus from Amazonia 
TABLE 1: Trypanosomatids isolates, host, geographic origin, and sequences of SSU rDNA and gGAPDH used for phylogenetic analysis.

\begin{tabular}{|c|c|c|c|c|c|}
\hline \multirow{2}{*}{ Trypanosomatids species } & \multirow{2}{*}{ Isolate code } & \multirow{2}{*}{ Host } & \multirow{2}{*}{ Geographic origin } & \multicolumn{2}{|c|}{ Accession number ${ }^{\mathrm{a}}$} \\
\hline & & & & gGAPDH & SSU rDNA \\
\hline & & Fish & & & \\
\hline Trypanosoma sp. & CLAR & Clarias angolensis & Africa & AJ620251 & \\
\hline Trypanosoma sp. & MARV & Cyprinus carpio & Czech Republic & AJ620248 & \\
\hline T. granulosum & Portugal & Anguilla anguilla & Portugal & AJ620247 & \\
\hline T. granulosum & UK & $\begin{array}{l}\text { Anguilla anguilla } \\
\text { Reptile }\end{array}$ & United Kingdom & AJ620246 & \\
\hline Trypanosoma sp. & Gecko & Tarentola annularis & Senegal & AJ620259 & \\
\hline T. varani & V54 & Varanus exanthematicus & Senegal & AJ620261 & \\
\hline Trypanosoma sp. & T610 & Caiman yacare & Brazil & EU596256 & EU596252 \\
\hline Trypanosoma sp. & T624 & Caiman yacare & Brazil & EU596257 & EU596253 \\
\hline Trypanosoma sp. & T625 & Caiman yacare & Brazil & & EU596259 \\
\hline Trypanosoma sp. & T1092 & Caiman yacare & Brazil & EU596258 & EU596254 \\
\hline Trypanosoma sp. & $\mathrm{T} 1100$ & Caiman yacare & Brazil & & EU596260 \\
\hline Trypanosoma sp. & T1101 & Caiman yacare & Brazil & & EU596261 \\
\hline Trypanosoma sp. & T1102 & Caiman yacare & Brazil & & EU596262 \\
\hline Trypanosoma sp. & T1119 & Caiman yacare & Brazil & & EU596263 \\
\hline Trypanosoma sp. & $\mathrm{T} 1120$ & Caiman yacare & Brazil & & EU596255 \\
\hline Trypanosoma sp. & СВT02 & $\begin{array}{l}\text { Caiman crocodilus } \\
\text { Bird }\end{array}$ & Brazil & JQ768791 & JQ768792 \\
\hline T. avium & Chaffinch & Fringilla coelebs & Czech Republic & AJ620263 & \\
\hline T. avium & Rook & $\begin{array}{l}\text { Corvus frugilegus } \\
\text { Mammals }\end{array}$ & Czech Republic & AJ620262 & \\
\hline T. conorhini & USP & Rattus rattus & Brazil & AJ620267 & \\
\hline T. cruzi marinkellei & B7 & Phyllostomus hastatus & Brazil & AJ620270 & \\
\hline T. cruzi & & & & X52898 & \\
\hline T. lewisi & L32 & Rattus rattus & & AJ620272 & \\
\hline T. microti & TRL132 & Microtus agrestis & England & AJ620273 & \\
\hline Trypanosoma sp. & $\mathrm{ABF}$ & Wallabia bicolor & Australia & AJ620276 & \\
\hline Trypanosoma sp. & R5 & Oryctolagus cuniculus & Australia & AJ620276 & \\
\hline T. theileri & K127 & Bos taurus & Germany & AJ620282 & \\
\hline Trypanosoma sp. & D30 & Cervus dama & Germany & AJ620279 & \\
\hline T. dionisii & P3 & Pipistrellus pipistrellus & United Kingdom & AJ620271 & \\
\hline T. vespertilionis & P14 & Pipistrellus pipistrellus & England & AJ620283 & \\
\hline T. brucei rhodesiense & 058 & Homo sapiens & Zambia & AJ620284 & \\
\hline T. vivax & Desowitz & Ovis aries & Nigeria & AJ620295 & \\
\hline T. vivax & & & & AF053744 & \\
\hline T. congolense Forest & Cam22 & Capra capra & Cameroon & AJ620289 & \\
\hline T. congolense Forest & TSW103 & Sus scrofa & Liberia & AJ620286 & \\
\hline T. evansi & & & & AF053743 & \\
\hline T. cyclops & LV492 & Macaca sp. & Malaysia & AJ620265 & \\
\hline T. minasense & LSTM & Saimiri boliviensis & South America & AJ620274 & \\
\hline T. rangeli & & & & AF053742 & \\
\hline & & Invertebrate & & & \\
\hline Crithidia fasciculata & & & & AF047493 & \\
\hline T. congolense Forest & ANR3 & Glossina palpalis & Gambia & AJ620285 & \\
\hline T. congolense Tsavo & 114 & Glossina pallidipes & Tanzania & AJ620291 & \\
\hline T. cruzi & $\mathrm{C} 8 \mathrm{cl} 2$ & Triatoma infestans & Bolivia & AJ620268 & \\
\hline T. cruzi & VINCH 89 & Triatoma infestans & Chile & AJ620269 & \\
\hline
\end{tabular}


TABLE 1: Continued.

\begin{tabular}{lclcr}
\hline Trypanosomatids species & Isolate code & Host & Geographic origin & \multicolumn{2}{c}{$\begin{array}{c}\text { Accession number }^{\mathrm{a}} \\
\text { gGAPDH }\end{array}$} \\
\hline T. grayi & ANR4 & Glossina palpalis & Gambia & AJ620257 \\
T. grayi & BAN1 & Glossina palpalis & Gambia & AJ620258 \\
T. simiae & Ken 2 & Glossina morsitans & Gambia & AJ620293 \\
T. godfreyi & Ken 7 & Glossina morsitans & Gambia & AJ620292 \\
T. simiae Tsavo & Ketri 1864 & Glossina pallidipes & Kenya & AJ620294 \\
Trypanosoma sp. & TL.AQ.22 & Philaemon sp. & Australia & AJ620280 \\
\hline
\end{tabular}

Sequences determined in this study and deposited in GenBank are underlined and bold.

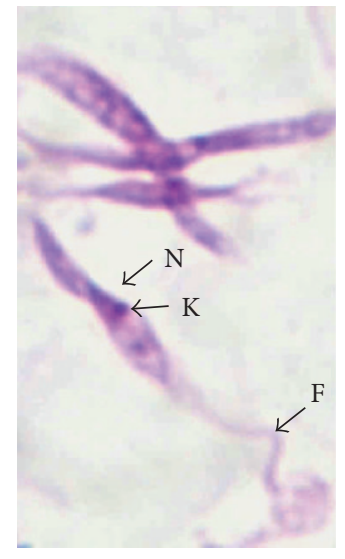

(a)

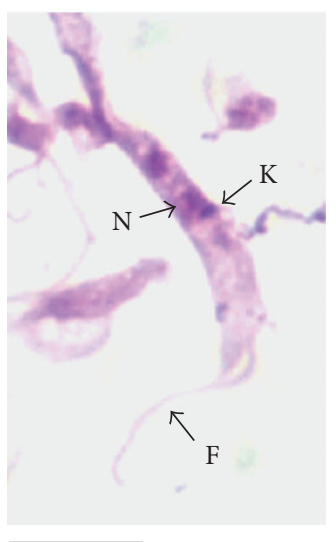

$10 \mu \mathrm{m}$

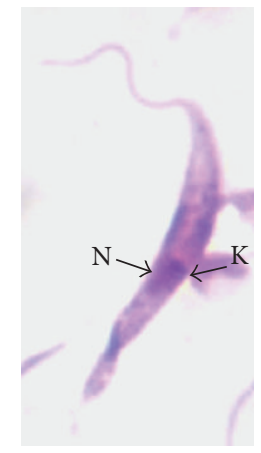

(b)

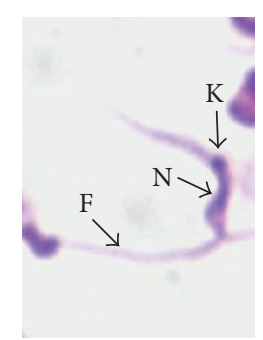

(d)

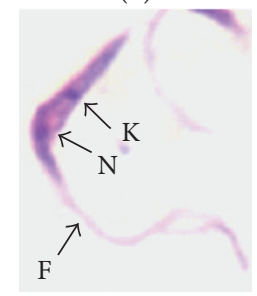

(e)
FIGURE 1: Microphotographs of Giemsa-stained trypanosome forms from Cayman crocodilus (CBT 02) obtained by in vitro culture (LIT). Epimastigotes forms $(a, b, c)$ and trypomastigotes forms $(d, e) . K$, kinetoplast; N, nucleus; F, flagellum.

[13]. Recently, trypanosomes isolates were obtained from C. yacare in Pantanal from Mato Grosso do Sul State and showed similar morphology of blood trypomastigote with Trypanosoma sp. described previously $[19,22]$. In this present study we obtained the first trypanosome isolate from $C$. crocodilus.
The prevalence of Trypanosoma sp. in C. yacare varies from 35 to $46 \%$ in different studies performed in Pantanal region from Mato Grosso do Sul state [19, 22]. Only one spectacled caiman captured in Mato Grosso was positive in hemoculture (33\%), but the prevalence in this species has not been established and a further study involving a large number of individuals (C. crocodilus) is necessary to determine the prevalence of Trypanosoma sp. and T. cecili.

Most studies of caiman trypanosomes were performed in the Pantanal region. The only study in Amazon with C. crocodilus and Paleosuchus trigonatus found a very low prevalence with rare trypomastigote forms in blood or tissue. This species was designated T. cecili and isolation has not yet been possible [13].

The epimastigotes forms in axenic culture of spectacled caiman isolate are very similar to Trypanosoma sp. from $C$. yacare from Pantanal (Figure 1). The tissue imprint forms of T. cecili and blood forms of Trypanosoma sp. from Pantanal are distinguishable, but similar tissue forms are detected in $C$. yacare and C. crocodilus $[13,19,22]$.

The variable V7-V8 region of SSU rDNA has been used for DNA barcoding of trypanosomatids and is able to distinguish all species, polymorphisms, and genetic relationships among closely related taxa $[18,19,29-33]$. In addition, the gGAPDH sequences were used to improve the phylogenetic analysis $[19,23,24,33]$. In all phylogenetic analyses inferred by V7-V8 SSU rDNA and gGAPDH the isolated CBT 02 was included in monophyletic branch called T. grayi Clade, together with Trypanosoma sp. from Brazilian caiman. The V7-V8 region segregated the Brazilian caimans isolates in two branches: Cay01 and Cay02. Most isolates were comprised of Cay01 genotype, probably the most prevalent in Pantanal region. The new isolate from C. crocodilus (CBT 02) nested in Cay01 genotype.

The phylogenetic positions of CBT02 isolate show that Trypanosoma sp. from Cay01 genotype I is able to infect two species of Caiman genus in Brazil. These findings clarify the morphological approaches in tissues imprints which have trypomastigote similar morphology in C. yacare and $C$. crocodilus.

The distribution of Cay01 genotype is not restricted to Pantanal region of Mato Grosso do Sul state and vertebrate host. The Confresa county is located in north of Mato Grosso state and comprises a mosaic of Amazonia and Cerrado biomes and is irrigated by Tocantins-Araguaia basin. The $C$. 


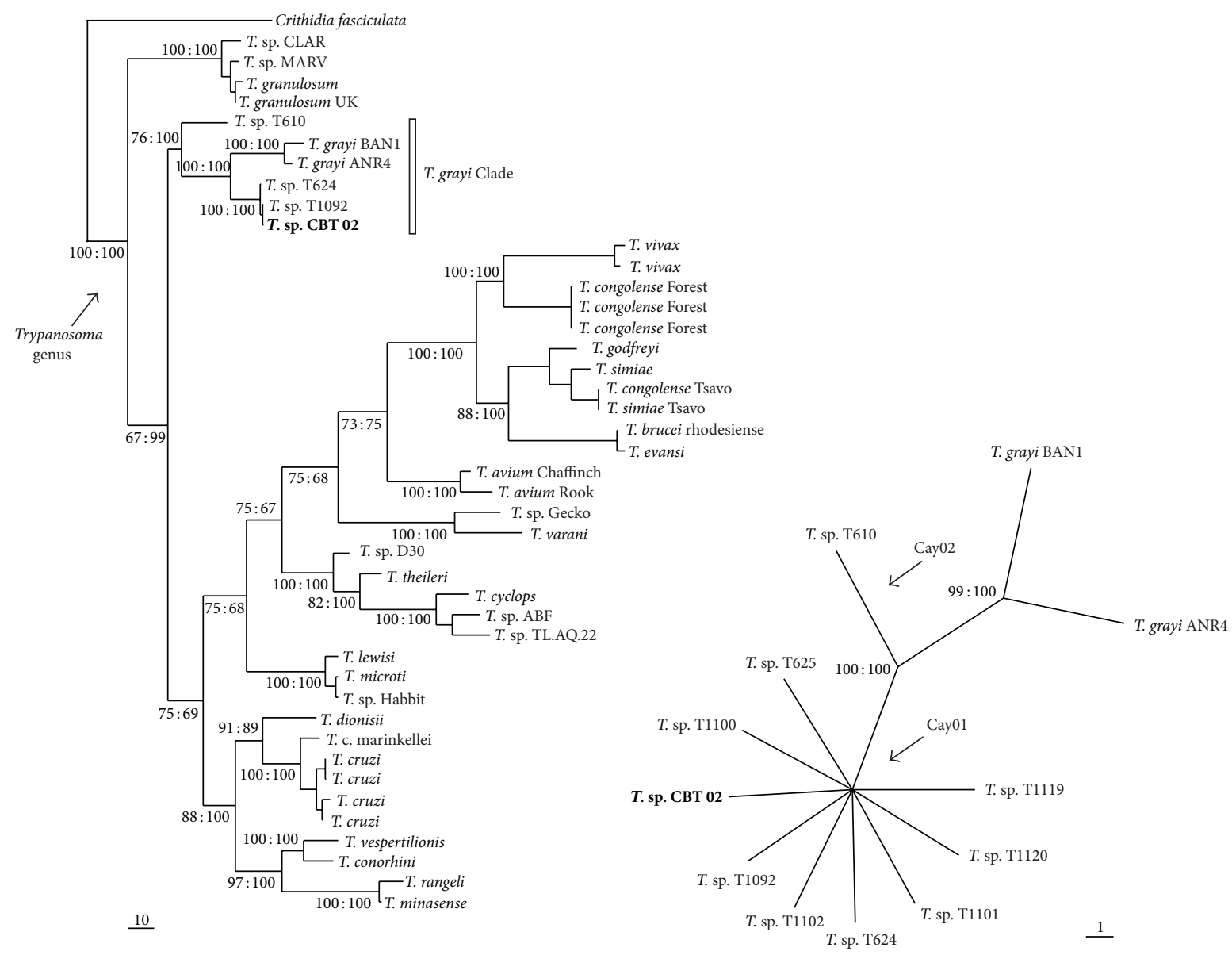

(a)

(b)

FIGURE 2: (a) Phylogenetic trees inferred by maximum parsimony and Bayesian methods based on gGAPDH gene sequences of 43 trypanosomes and Crithidia fasciculata as outgroup (515 characters, 34 parsimony informative). (b) Dendogram inferred by parsimony analyses based on V7-V8 SSU rDNA sequences from 12 crocodilian trypanosomes isolates (734 characters, 24 parsimony informative). Numbers at nodes show bootstrap (first) and posterior probabilities (second) values for MP and BI, respectively. The support values for the major branches are derived from 500 replicates, respectively, for MP.

yacare occurred in upper Madeira system of the Amazon basin and Paraguay River and lower Paraná system including Brazil, Bolivia, Paraguay, and Argentina. C. crocodiles occur in both Amazon and Orinoco drainage $[2,5]$. According to Brazaitis et al. [34], sympatric areas occur in Mato Grosso and Rondônia states. However, in Tocantins-Araguaia basin only C. crocodilus occurs.

The presence of the same trypanosome species in C. yacare and C. crocodilus indicates transmission cycles between these species evidencing sympatry of caiman species or exposure to the same vector. The T. grayi in Africa is transmitted by tse-tse flies [35]. In Brazil, different species of tabanids can bite reptiles like C. crocodilus and Eunectes murinus [36]. The low host specificity of tabanids and host switch of caiman trypanosomes suggest an important role of insects in the transmission cycle of these parasites in Brazil.

The addition of new isolates of caiman trypanosomes of different vertebrate hosts is necessary for better understanding of diversity and phylogenetic relationships of these parasites and demonstrates the low host specificity of cayman trypanosomes in Brazil.

\section{Acknowledgments}

The authors are grateful to several people for their invaluable help during capture. This research was financially supported by Fundação de Amparo a Pesquisa do Estado de São Paulo (FAPESP). Solange M. Gennari and Antonio H. H. Minervino are in receipt of a fellowship from CNPq and Arlei Marcili, Herbert S. Soares, Julia T. R. de Lima, ATLM, and Igor C. L. Acosta from FAPESP.

\section{References}

[1] A. Janke, A. Gullberg, S. Hughes, R. K. Aggarwal, and U. Arnason, "Mitogenomic analyses place the gharial (Gavialis gangeticus) on the crocodile tree and provide pre-K/T divergence times for most crocodilians," Journal of Molecular Evolution, vol. 61, no. 5, pp. 620-626, 2005. 
[2] J. P. Roos, Crocodiles. Status Survey and Conservation Action Plan, VIII 96, IUCN/ SS, Crocodile Specialist Group, Gland, Switzerland, 2nd edition, 1998.

[3] F. Medem, Los Crocodylia De Sur America 1, Colciencias, Bogotá, Colombia, 1981.

[4] F. W. King and R. L. Burke, Crocodilian, Tuatara and Turtle Species of the World. A Taxonomic and Geographic Reference, Association of Systematics Collections, Washington, DC, USA, 1989.

[5] A. Velasco and J. Ayarzagüena, "Spectacled Caiman Caiman crocodilos," in Crocodiles, Status Survey and Conservation Action Plan, S. C. Manolis and C. Stenvenson, Eds., 3rd edition, 2010.

[6] K. Junker, D. R. Brooks, and J. Boomker, "Proctocaecum gairhei n. sp. (Digenea: Cryptogonimidae: Acanthostominae) from Gavialis gangeticus (Gmelin) in Nepal and a revised cladogram of Proctocaecum Baugh, 1957," Systematic Parasitology, vol. 71, no. 3, pp. 229-236, 2008.

[7] V. V. Tkach, E. J. Strand, and L. Froese, "Macroderoides texanus n. sp. (Digenea: Macroderoididae) from alligator gar, Atractosteus spatula in Texas," Parasitology Research, vol. 104, no. 1, pp. 27-33, 2008.

[8] L. J. La Grange, G. Marucci, and E. Pozio, “Trichinella zimbabwensis in wild Nile crocodiles (Crocodylus niloticus) of South Africa," Veterinary Parasitology, vol. 161, no. 1-2, pp. 88-91, 2009.

[9] L. J. La Grange, D. Govender, and S. Mukaratirwa, "The occurrence of Trichinella zimbabwensis in naturally infected wild crocodiles (Crocodylus niloticus) from the Kruger National Park, South Africa," Journal of Helminthology, vol. 16, pp. 1-6, 2012.

[10] A. R. Waddle, J. M. Kinsella, J. P. Ross, E. Rojas-Flores, H. F. Percival, and D. J. Forrester, "Nematodes collected by gastric lavage from live American Alligators, Alligator mississippiensis, in Florida," Journal of Parasitology, vol. 95, no. 5, pp. 1237-1238, 2009.

[11] L. A. Viana and E. J. Marques, "Haemogregarine parasites (Apicomplexa: Hepatozoidae) in Caiman crocodilus yacare (Crocodilia: Alligatoridae) from Pantanal, Corumbá, MS, Brazil," Revista Brasileira de Parasitologia Veterinária, vol. 14, no. 4, pp. 173-175, 2005.

[12] L. A. Viana, F. Paiva, M. E. Coutinho, and R. Lourenço-DeOliveira, "Hepatozoon caimani (Apicomplexa: Hepatozoidae) in Wild Caiman, Caiman yacare, from the Pantanal Region, Brazil," Journal of Parasitology, vol. 96, no. 1, pp. 83-88, 2010.

[13] R. Lainson, "Trypanosoma cecili n. sp., a parasite of the South American cayman, Caiman crocodilus crocodilus (Linnaeus, 1758) (Crocodilia: Alligatoridae)," Protozoology, vol. 3, pp. 8793, 1977.

[14] C. A. Hoare, The Trypanosomes of Mammals: A Zoological Monograph, Blackwell Scientific, Oxford, UK, 1972.

[15] K. Vickerman, "The evolutionary expansion of the trypanosomatid flagellates," International Journal for Parasitology, vol. 24, no. 8, pp. 1317-1331, 1994.

[16] J. R. Stevens, H. A. Noyes, C. J. Schofield, and W. Gibson, "The molecular evolution of trypanosomatidae," Advances in Parasitology, vol. 48, pp. 1-56, 2001.

[17] A. G. B. Simpson, J. R. Stevens, and J. Lukeš, "The evolution and diversity of kinetoplastid flagellates," Trends in Parasitology, vol. 22, no. 4, pp. 168-174, 2006.

[18] R. C. Ferreira, A. A. De Souza, R. A. Freitas et al., "A phylogenetic lineage of closely related trypanosomes (Trypanosomatidae, Kinetoplastida) of anurans and sand flies (Psychodidae,
Diptera) sharing the same ecotopes in Brazilian Amazonia," Journal of Eukaryotic Microbiology, vol. 55, no. 5, pp. 427-435, 2008.

[19] L. B. Viola, M. Campaner, C. A. Takata et al., "Phylogeny of snake trypanosomes inferred by SSU rDNA sequences, their possible transmission by phlebotomines, and taxonomic appraisal by molecular, cross-infection and morphological analysis," Parasitology, vol. 135, no. 5, pp. 595-605, 2008.

[20] S. R. Telford, “The kinetoplastid hemoflagellates of reptiles," in Parasitic Protozoa, J. P. Kreier, Ed., vol. 10, Academic press, San Diego, Calif, USA, 2nd edition, 1995.

[21] L. Lloyd, W. B. Johnson, and W. A. Young, "The trypanosome infections of tsetse flies in northern Nigeria and a new method of estimation," in Bulletin of Entomology Research, vol. 14, pp. 265-288, 1924.

[22] V. L. B. Nunes and E. T. Oshiro, “Trypanosoma sp. em jacar, Caiman crocodilus yacare (Daudin, 1802) (Crocodilia: Alligatoridae)," Semina, vol. 11, pp. 62-65, 1990.

[23] P. B. Hamilton, J. R. Stevens, M. W. Gaunt, J. Gidley, and W. C. Gibson, "Trypanosomes are monophyletic: evidence from genes for glyceraldehyde phosphate dehydrogenase and small subunit ribosomal RNA," International Journal for Parasitology, vol. 34, no. 12, pp. 1393-1404, 2004.

[24] P. B. Hamilton, W. C. Gibson, and J. R. Stevens, "Patterns of co-evolution between trypanosomes and their hosts deduced from ribosomal RNA and protein-coding gene phylogenies," Molecular Phylogenetics and Evolution, vol. 44, no. 1, pp. 15-25, 2007.

[25] J. D. Thompson, T. J. Gibson, F. Plewniak, F. Jeanmougin, and D. G. Higgins, "The CLUSTAL X windows interface: flexible strategies for multiple sequence alignment aided by quality analysis tools," Nucleic Acids Research, vol. 25, no. 24, pp. 48764882, 1997.

[26] K. B. Nicholas, H. B. Nicholas Jr., and D. W. Deerfield, "GeneDoc: analysis and visualization of genetic variation," EMBNEW NEWS, vol. 4, p. 14, 1997.

[27] D. L. Swofford, "PAUP*: Phylogenetic Analysis Using Parsimony (and Other Methods), Beta Version 4. 0b10," Sinauer and Associates, Sunderland, Mass, USA, 2002.

[28] J. P. Huelsenbeck and F. Ronquist, "MRBAYES: bayesian inference of phylogenetic trees," Bioinformatics, vol. 17, no. 8, pp. 754-755, 2001.

[29] F. M. Da Silva, H. Noyes, M. Campaner et al., "Phylogeny, taxonomy and grouping of Trypanosoma rangeli isolates from man, triatomines and sylvatic mammals from widespread geographical origin based on SSU and ITS ribosomal sequences," Parasitology, vol. 129, no. 5, pp. 549-561, 2004.

[30] A. P. Cortez, R. M. Ventura, A. C. Rodrigues et al., "The taxonomic and phylogenetic relationships of Trypanosoma vivax from South America and Africa," Parasitology, vol. 133, no. 2, pp. 159-169, 2006.

[31] A. C. Rodrigues, F. Paiva, M. Campaner, J. R. Stevens, H. A. Noyes, and M. M. G. Teixeira, "Phylogeny of Trypanosoma (Megatrypanum) theileri and related trypanosomes reveals lineages of isolates associated with artiodactyl hosts diverging on SSU and ITS ribosomal sequences," Parasitology, vol. 132, no. 2, pp. 215-224, 2006.

[32] A. Marcili, V. C. Valente, S. A. Valente et al., "Trypanosoma cruzi in Brazilian Amazonia: lineages TCI and TCIIa in wild primates, Rhodnius spp. and in humans with Chagas disease associated with oral transmission," International Journal for Parasitology, vol. 39, no. 5, pp. 615-623, 2009. 
[33] M. Cavazzana Jr., A. Marcili, L. Lima et al., "Phylogeographical, ecological and biological patterns shown by nuclear (ssrRNA and gGAPDH) and mitochondrial (Cyt b) genes of trypanosomes of the subgenus Schizotrypanum parasitic in Brazilian bats,' International Journal for Parasitology, vol. 40, no. 3, pp. 315-320, 2010.

[34] P. Brazaitis, M. E. Watanabe, and G. Amato, "The caiman trade," Science American, vol. 278, pp. 52-58, 1998.

[35] J. J. McNamara and W. F. Snow, "Improved identification of Nannomonas infections in tsetse flies from The Gambia," Acta Tropica, vol. 48, no. 2, pp. 127-136, 1990.

[36] R. L. M. Ferreira, A. L. Henriques, and J. A. Rafael, "Activity of tabanids (Insecta: Diptera: Tabanidae) attacking the reptiles Caiman crocodilus (Linn.) (Alligatoridae) and Eunectes murinus (Linn.) (Boidae), in the Central Amazon, Brazil," Memorias do Instituto Oswaldo Cruz, vol. 97, no. 1, pp. 133-136, 2002. 

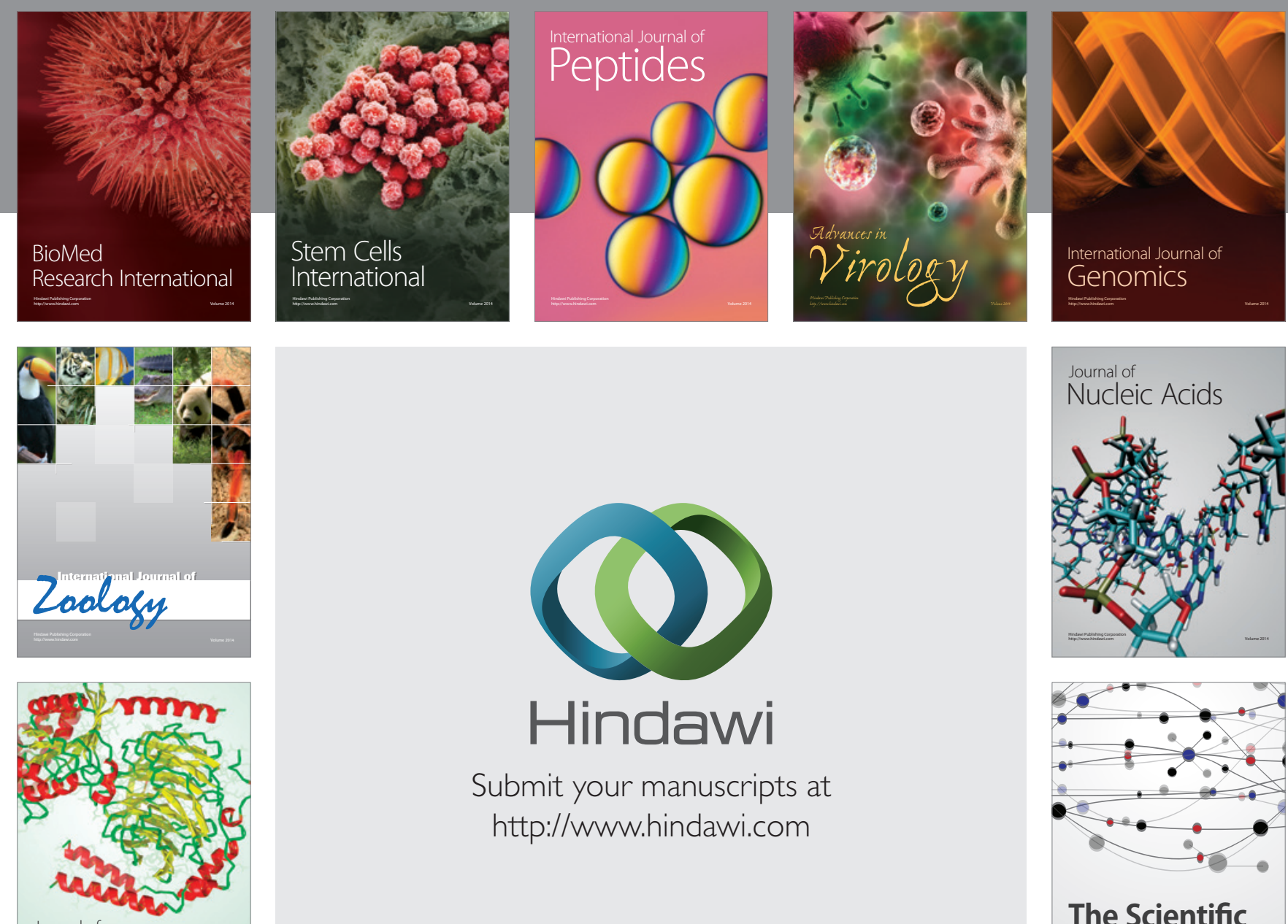

Submit your manuscripts at

http://www.hindawi.com

Journal of
Signal Transduction
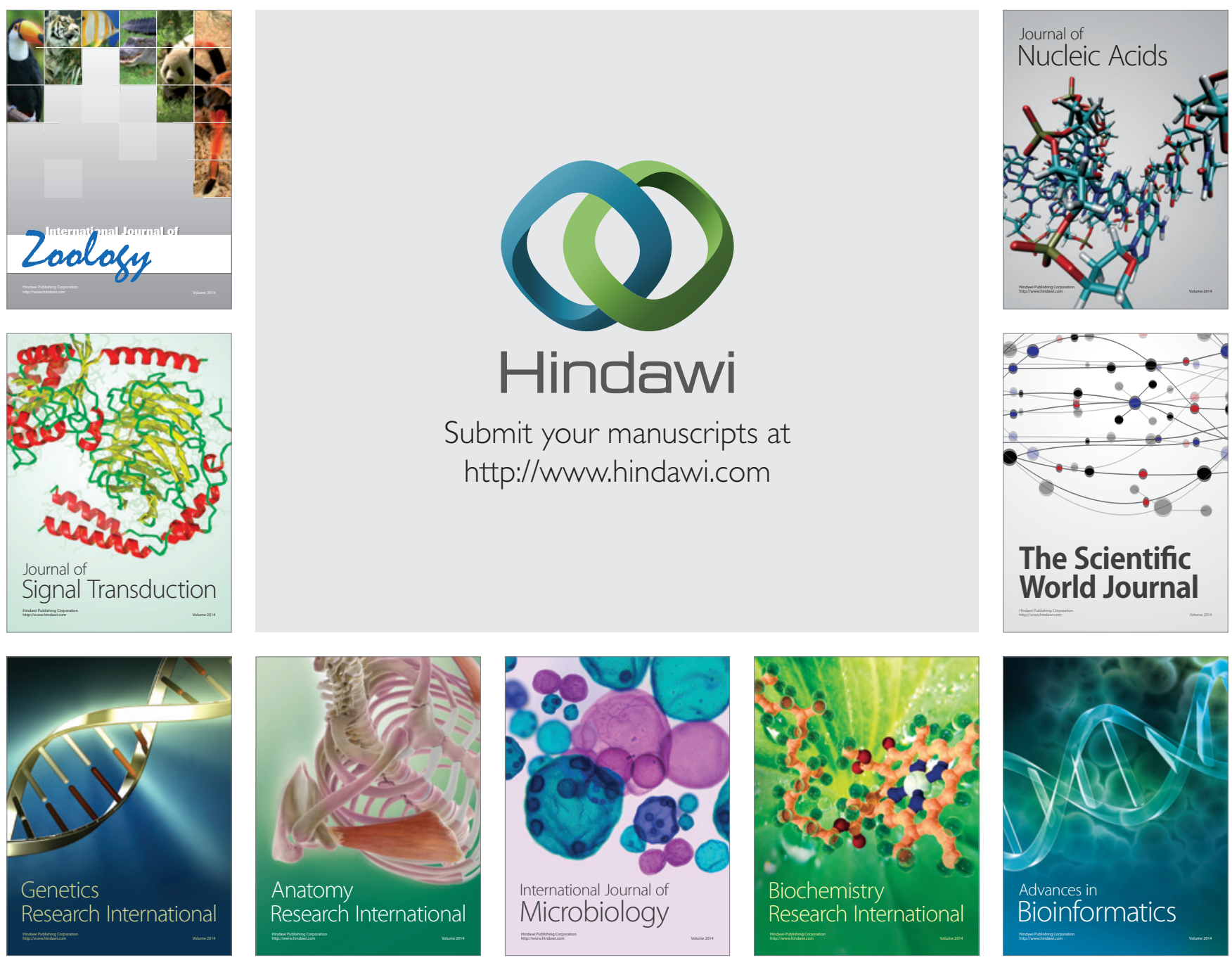

The Scientific World Journal
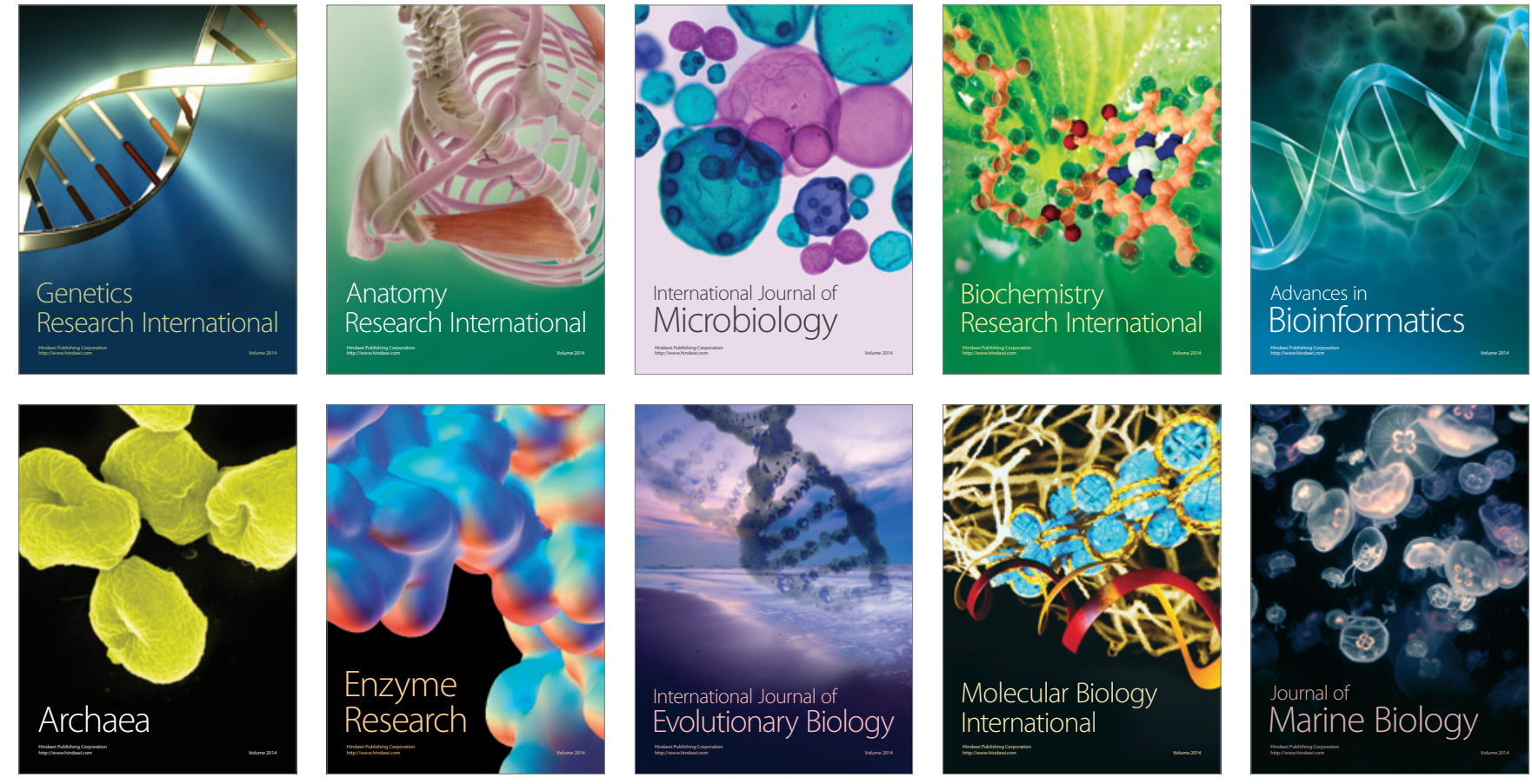